\title{
Org2766 improves performance of rats with unilateral lesions in the fimbria fornix in a spatial learning task
}

\author{
Berry Spruijt ${ }^{1}$, Nikolaos Pitsikas ${ }^{2}$, Sergio Algeri ${ }^{2}$ and Willem Hendrik Gispen ${ }^{1}$ \\ ${ }^{\prime}$ Division of Molecular Neurobiology, Rudolf Magnus Institute, Institute of Molecular Biology and Medical Biotechnology, University of \\ Utrecht, Utrecht (The Netherlands) and 'Istituto di Ricerche Farmacologiche, 'Mario Negri', Milano (Italy)
}

(Accepted 13 March 1990)

Key words: Fimbria fornix; Functional recovery; $\mathrm{ACTH}_{4-9}$ analog; Spatial learning; Avoidance behavior

\begin{abstract}
ACTH and related peptides are known for their effects on behavior and for their efficacy on peripheral nerve regeneration. More recently, evidence demonstrating neurotrophic effects of Org2766 on recovery after damage of the central nervous system has become available. Aging studies indicated that particularly the hippocampus appears susceptible to peptide treatment. Therefore, in this study the neurotrophic influence of Org2766 on recovery of hippocampal functioning was studied after transection of the fimbria fornix connection. Analogous to results obtained with recovery of sensorimotor function following peripheral nerve damage a chronic treatment with Org2766 facilitates recovery of the impaired function, i.e. spatial learning in a Morris maze. However, the lesion-induced impairment of avoidance behavior was not influenced by the peptide treatment.
\end{abstract}

\section{INTRODUCTION}

A variety of compounds such as certain peptides, proteins, e.g. nerve growth factor, exert their neurotrophic action on developing and regenerating nerves ${ }^{7}$. Peripheral administration of ACTH and related peptides has facilitatory effects on functional and morphological recovery of damaged peripheral nerves ${ }^{7}$.

The $\mathrm{ACTH}_{4-9}$ analog, Org2766 (H-Met $\left(\mathrm{O}_{2}\right)$-Glu-HisPhe-DL-Lys-Phe-OH), which has no corticotrophic activity ${ }^{10}$, also affects recovery of function after brain damage. Behavioral recovery of hyperemotionality in rats lesioned in the septal area ${ }^{14}$ was accelerated in Org2766-treated rats. This peptide also facilitated recovery of function in rats bearing bilateral lesions in the parafascicular areas as tested in a reversal learning paradigm ${ }^{20}$. Disrupted locomotor activity after a 6-OHDA lesion was facilitated both after peripheral and local administration of the peptide in the nucleus accumbens ${ }^{32}$.

In addition, in aging rats the $\mathrm{ACTH}_{4-9}$ analog counteracts an age-related decrease in performance. In a longitudinal study chronic treatment of aged rats resulted in enhanced social attention ${ }^{28}$ and improved spatial orientation $^{29}$. Evidence is available that the limbic system is involved in Org2766-induced behavioral changes in aging animals. Org2766 reduced the morphological correlates of brain aging in the hippocampus ${ }^{16}$ and improved spatial orientation in Org2766-treated aged rats ${ }^{29}$, a task commonly associated with hippocampal functioning. In addition, disrupted spatial orientation ${ }^{4}$ and also afferents and efferents to the hippocampus seem vulnerable to aging ${ }^{9}$. Therefore, in the present study a fimbria fornix (FF) lesion was used to further explore the trophic effects of Org2766 on recovery from impaired hippocampal functioning; rats with unilateral lesions in the FF were chronically treated with this peptide. Behavioral deficits induced by $\mathrm{FF}$ lesions have been described in various tasks involving spatial orientation ${ }^{18,19,21,22,24}$. The abovementioned results are in line with the hypothesis that Org2766 may exert trophic effects on brain damage, which occurs as a consequence of either lesioning or aging. In the present study learning was investigated in a Morris maze which is particularly useful for analyzing the role of the hippocampus in spatial learning and memo$\mathrm{ry}^{18}$. The performance in an avoidance task was also measured, because it seems less dependent on spatial orientation.

\section{MATERIALS AND METHODS}

Animals
Sixty-five male Wistar rats (TNO, Zeist, The Netherlands)
weighing $220-240$ g upon lesioning of the FF were used. The animals
were randomly divided into 4 groups: sham-operated treated with
saline ( $n=17$, sham-sal), sham-operated treated with Org2766 ( $n$

Correspondence: B.M. Spruijt, Institute of Molecular Biology and Medical Biotechnology, University of Utrecht, Padualaan 8, 3584 CH Utrecht, The Netherlands. 
$=16$, sham-Org2766), FF-lesioned treated with saline $(n=17$, FF-sal) and FF-lesioned treated with Org2766 ( $n=15$, FFOrg2766). Animals were housed in groups of 4-5 in Makrolon cages in a temperature $\left(21 \pm 1{ }^{\circ} \mathrm{C}\right)$ - and light-controlled room with reversed day/night cycle (red light was switched on at $08.00 \mathrm{~h}$ and switched off at $20.00 \mathrm{~h}$ ). Food and tap water were available ad libitum. To avoid any stress due to transportation or any other change in environmental circumstances all experiments were carried out in the room where only these animals were housed and took place between 10.00 and $15.00 \mathrm{~h}$. After lesioning the animals were allowed to recover for 2 weeks. The experiments started when they had reached their preoperative body weight.

\section{Lesion and treatment}

Unilateral partial transection of the left FF was performed using a method presented by Hefti et al. ${ }^{12}$. The rats were anesthetized with a subcutaneous injection of Hypnorm (Duphar, Weesp, The Netherlands) containing flunisone $(10 \mathrm{mg} / \mathrm{mil})$ and phetanylcitrate $(0.2 \mathrm{mg} / \mathrm{ml})$. After placement in the stereotactor, a specially designed knife ${ }^{12}$ was lowered into the brain at $0.1 \mathrm{~mm}$ posterior from bregma and moved laterally from 1.0 to $5.0 \mathrm{~mm}$ at a depth of $6.5 \mathrm{~mm}$. Corrected for the difference in body weight the location corresponds with the coordinates $2.0 \mathrm{~mm}$ posterior from bregma according to the atlas of Paxinos and Watson ${ }^{22}$ (see Figs. 64 and 17). In the sham-operated animals the knife was moved at a depth of 1 $\mathrm{mm}$. The distance between bregma and interaural line was about 8 $\mathrm{mm}$. Starting on the day of the lesion the sham-operated and the lesioned animals were treated with either saline or the $\mathrm{ACTH}_{4-9}$ analog Org2766, a gift from Organon BV (Oss, The Netherlands). Seven injections, $1 \mu \mathrm{g}$ per animal $/ 48 \mathrm{~h}$, were given subcutaneously in an injection volume of $0.5 \mathrm{ml}$ starting on the day of the lesion. All animals were subjected to the following sequence of behavioral tests: Morris maze and passive avoidance. Behavioral testing began 16 days after the lesion, $48 \mathrm{~h}$ after the last injection to avoid acute effects of the peptide treatment.

\section{Morris water task}

The water maze was a circular pool, $110 \mathrm{~cm}$ in diameter and 50 $\mathrm{cm}$ deep; the inner side was covered with white plastic. The tank was filled with warm water $(25 \mathrm{~cm})$ of approximately $26^{\circ} \mathrm{C}$, mixed with chalk powder. A wire mesh platform ( $8 \mathrm{~cm}$ diameter) was placed in the pool, $1 \mathrm{~cm}$ below the surface of the fluid. Behavioral tests were performed under dim red light conditions. The pool was located in a large observation room, with external cues outside the pool. These cues were kept unchanged throughout the period of testing. A trial started by placing a rat into the water facing the wall of the pool at one of 4 starting points, which divided the pool into 4 quadrants of equal size. The platform was located in a constant position in the middle of quadrant 2 , equidistant from the center and the edge of the pool. The animal received a block of 4 trials with an inter-trial interval of $1 \mathrm{~min}$ on 5 consecutive days with a different sequence of starting points on every day. If the rat did not find the platform within $120 \mathrm{~s}$, it was placed on it at the end of the trial by the experimentor and remained there for $30 \mathrm{~s}$, subsequently a score of $120 \mathrm{~s}$ was given. On day 5, after the last block of acquisition trials, a single trial was carried out: the rat was allowed to swim for $60 \mathrm{~s}$ in the pool without platform to assess the searching strategy of the animals. Swimming patterns were registered by a computerized image analysis system. Hardware consisted of an IBM AT computer combined with a PC vision frame grabber (Imaging Technology Inc., U.S.A.) and a CCD camera. Software for this application was developed in collaboration with Difa Measuring Systems BV (Breda, The Netherlands).

\section{Passive avoidance behavior}

Three days after the Morris maze test passive avoidance behavior was measured according to the procedure described by Ader et al. ${ }^{1}$. Rats were subjected to 3 pre-training trials and 1 training trial with shock. After entering the dark compartment with 4 paws, the guillotine door was closed and a shock of $0.4 \mathrm{~mA}$, lasting $2 \mathrm{~s}$, was

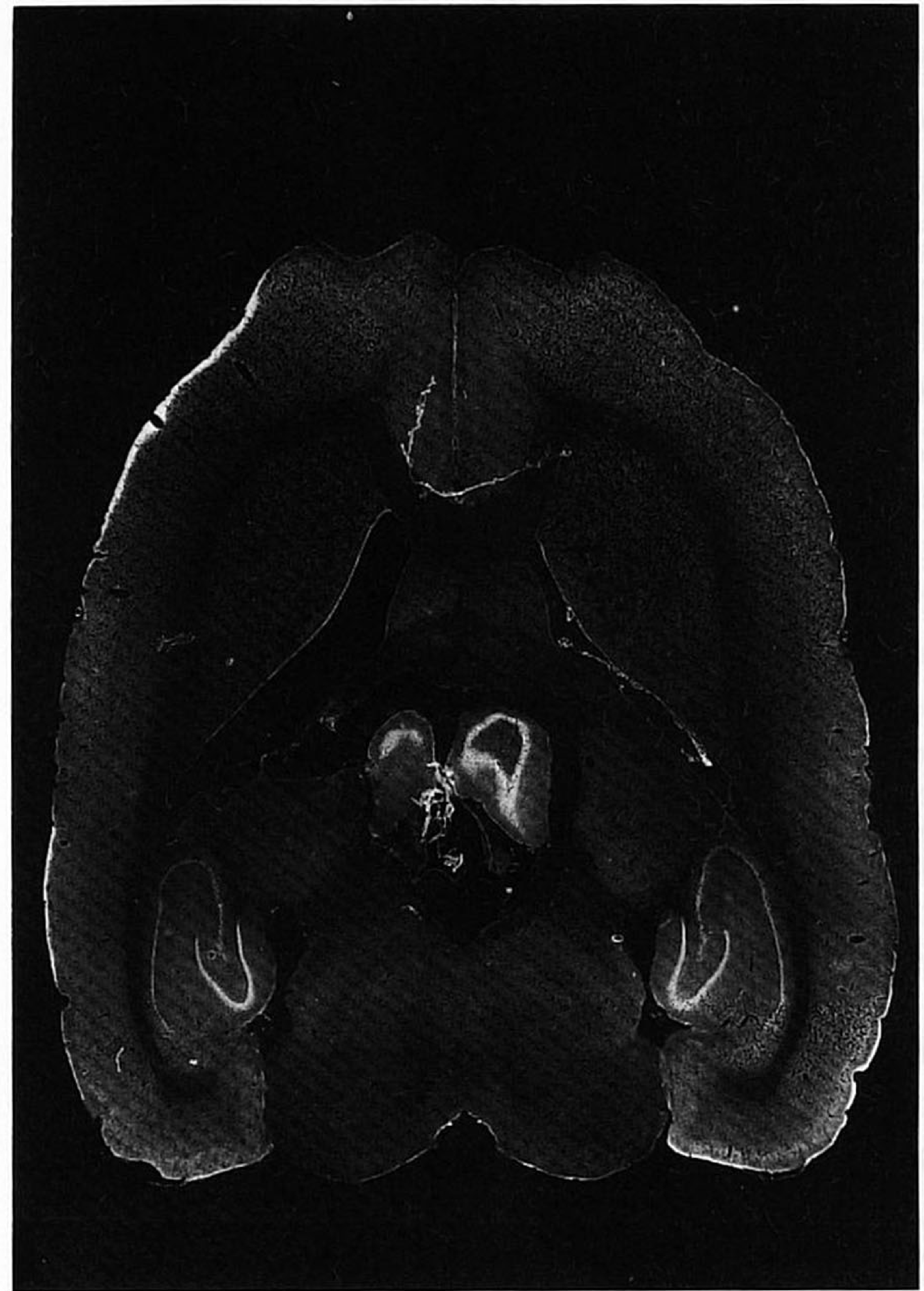

Fig. 1. Transection of the fimbria fornix at the left side of this horizontal section (see text).

given. Time to reenter (latency), with a maximum of $300 \mathrm{~s}$ was measured $24 \mathrm{~h}$ after the shock.

\section{Statistical analysis}

For the analysis of the effects of surgery and drug treatment over the days an analysis of variance on two factors (surgery and treatment) with repeated measurements was used on latency and the length of the swimming path. These overall ANOVAs were followed by ANOVAs on 2 factors per day. For assessing differences between group means per day ANOVAs were followed by a Tukey HSD procedure. The length of the covered distance per quadrant was expressed as percentage of the total distance. For comparing the length of the swimming path in the previously reinforced quadrant (2) with the other quadrants (1, 3 and 4), a Friedman analysis followed by a Wilcoxon test was used. For comparing the means of the groups per quadrant ANOVAs followed by a Tukey HSD test were done. A Kruskall-Wallis test was used for evaluating the latency of passive avoidance behavior. All statistical calculations were performed using the statistical package SYSTAT (Wilkinson, Leland, SYSTAT: The System for Statistics, SYSTAT, Inc., Evanston, IL, 1988).

\section{RESULTS}

Histological verification of the site of the lesion yielded results as shown in Fig. 1, therefore, data of all animals were used for further analysis. It must be noted that damage is not restricted to the FF connection but may involve damage to thalamic nuclei. The results obtained 


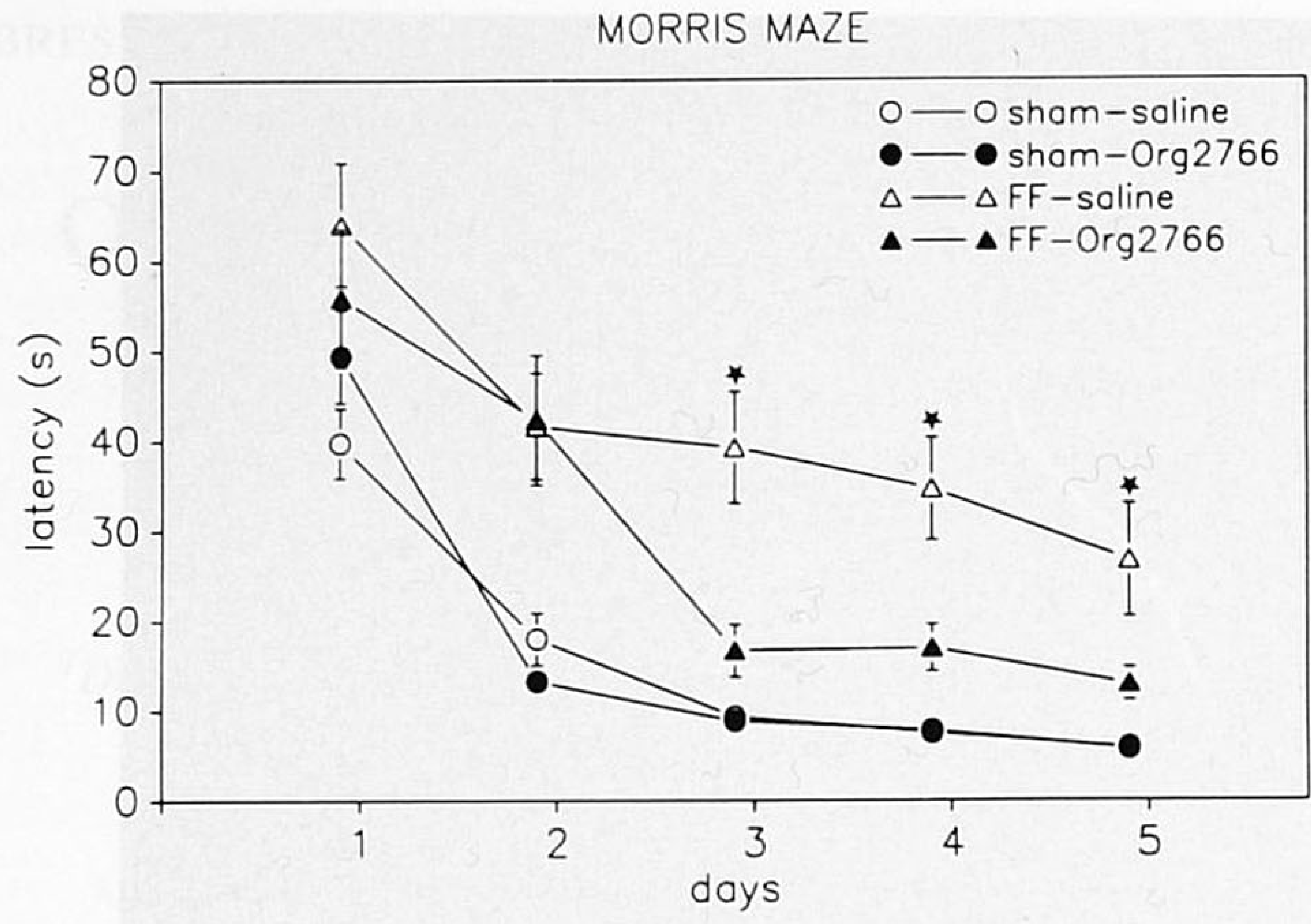

Fig. 2. The latencies to find the platform (mean \pm S.E.M.) over the 5 test days in the Morris maze for the sham-sal, sham-Org2766, FF-sal and the FF-Org2766 groups are shown. An ANOVA yielded a significant interaction between drug treatment and the lesion. Note the effect of Org2766 on the FF-lesioned group. * Indicates a significant difference between the FF-sal and FF-Org2766 animals (Tukey HSD test).

in the Morris maze are depicted in Fig. 2 (latency), Fig. 3 (distance) and Fig. 4 (trial without platform). Data from the passive avoidance task are shown in Fig. 5.

The 4 groups: sham-sal, sham-Org2766, FF-sal and FF-Org2766 showed improvement as measured by latencies and distances (Figs. 2 and 3 ) over the days, though not to the same extent.

The analysis of variance for 2 factors (drug treatment and surgery) with repeated measurements (days) showed a significant overall effect of the surgery on latency: $F_{1,61}$ $=34.28 ; P<0.001$. For the swum distance, significant overall effects were seen for the factor drug treatment: $F_{1,61}=4.7 ; P<0.03$, and the factor surgery: $F_{1,61}=$ 58.4; $P<0.0001$. In addition, an overall interaction was seen between drug treatment and surgery which is

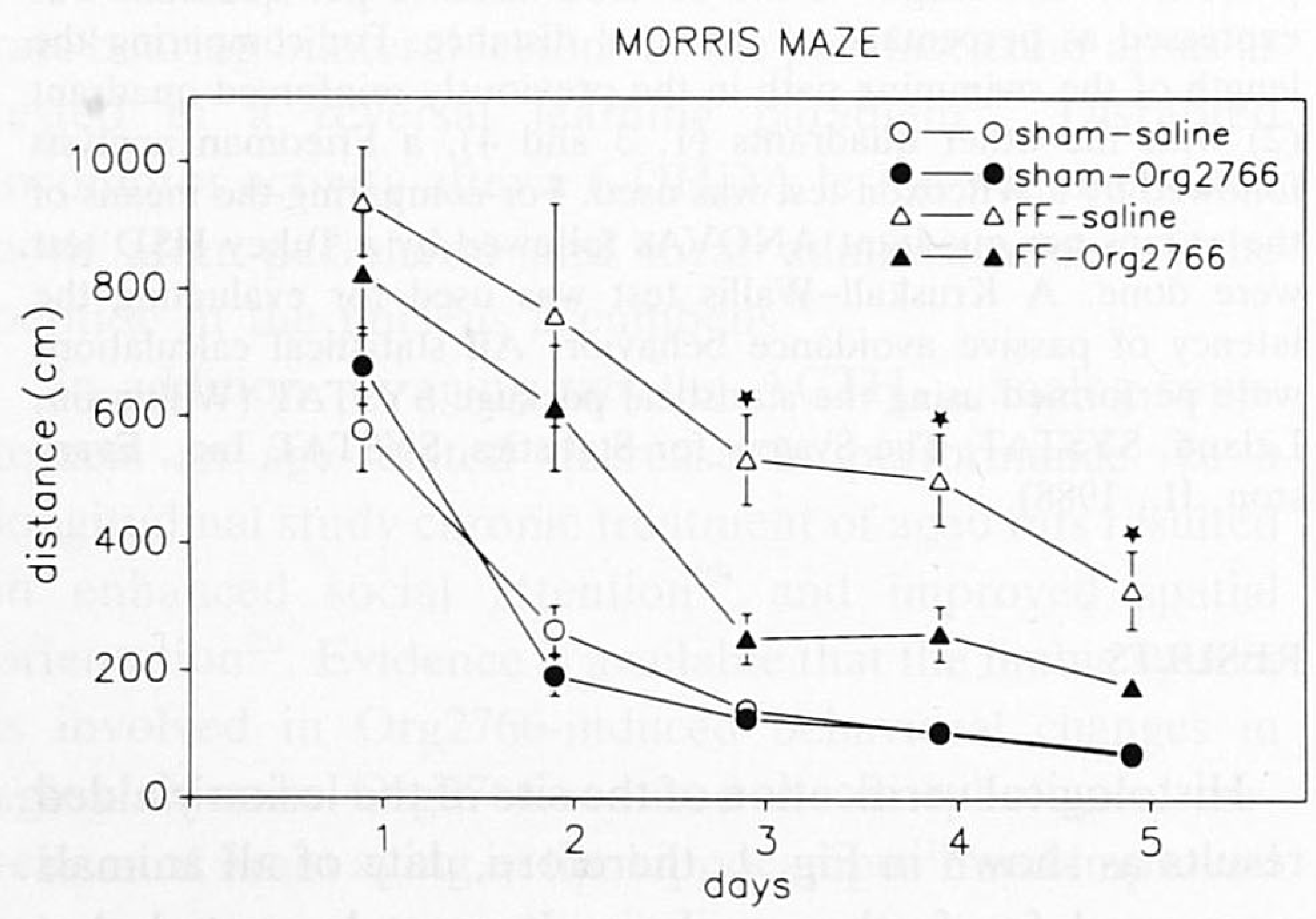

Fig. 3. The distance $(\mathrm{cm})$ swum to find the platform in the Morris maze (mean \pm S.E.M.). Experimental groups and abbreviations as in Fig. 2.

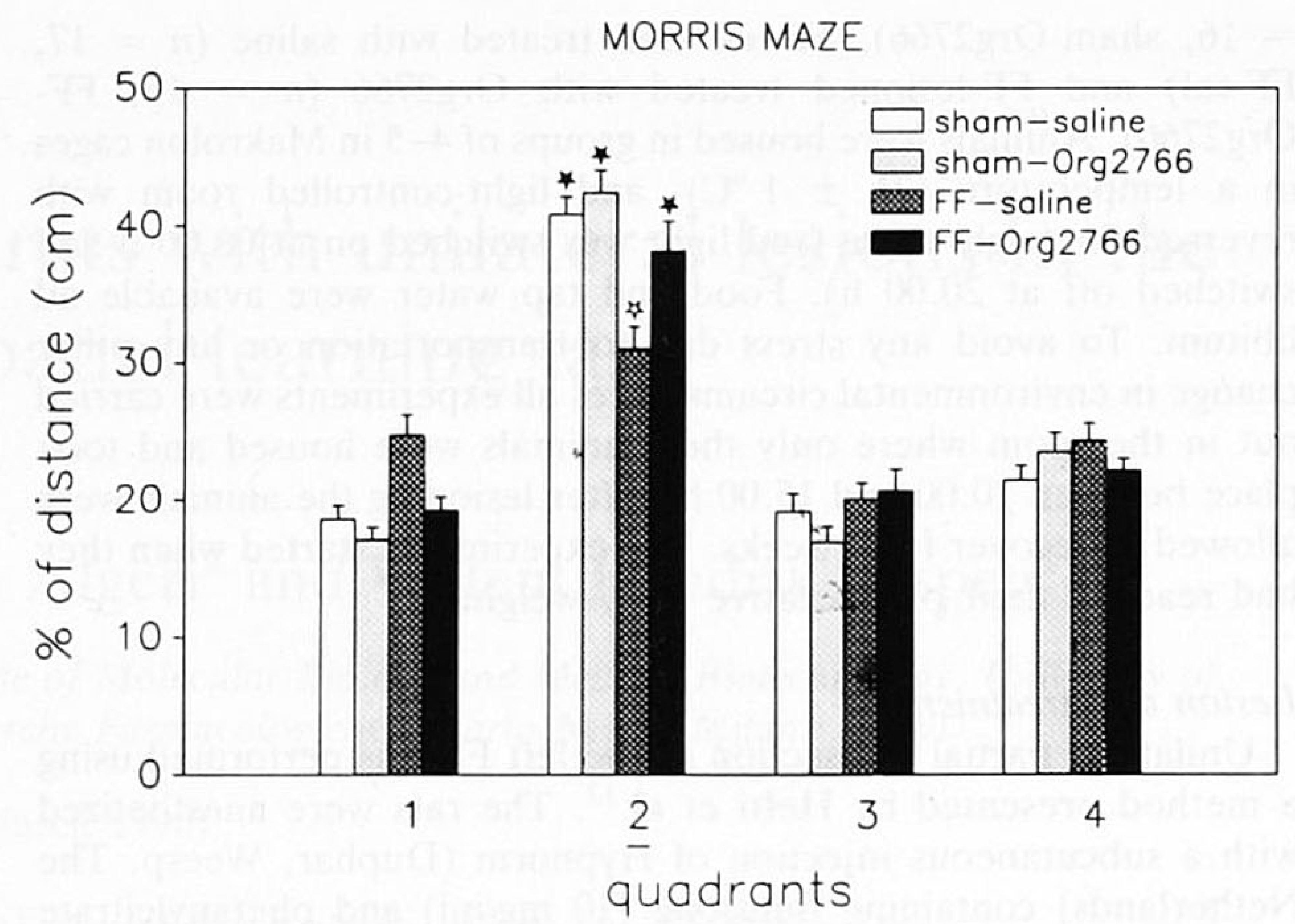

Fig. 4. The distance $(\mathrm{cm})$, swum in the 4 quadrants upon removal of the platform from quadrant 2 , is expressed as percentages from the total covered distance. ${ }^{*}$ Indicates a significant difference between the FF-Org2766 group vs the other 3 quadrants. indicates a significant difference between the FF-saline group and the other three groups.

illustrated by the improvement of $\operatorname{Org} 2766$ on the performance of lesioned animals and not on the shamoperated animals; latency $\left(F_{1,61}=4.316 ; P<0.042\right.$; see Fig. 2). Also for the swum distance, a significant interaction between drug treatment and surgery was found: $F_{1,61}=4.4 ; P<0.038$ (see Fig. 3). All groups showed an improvement over the days as a consequence of training both on latency: $F_{4,244}=91.97 ; P<0.0002$ and distance: $F_{4,244}=96.9 ; P<0.0001$. Interestingly, a significant overall interaction of trials with drug treatment and surgery $-F_{4,244}=2.65 ; P<0.03$ - was seen, as is indicated by the effect of Org2766 on the latency of lesioned animals on days 3, 4 and 5 (Fig. 2). A similar interaction (trials with drug treatment and surgery) was seen on distance: $F_{4,244}=2.44 ; P<0.047$, as is illustrated in Fig. 3.

Univariate $F$-tests performed on the data per day

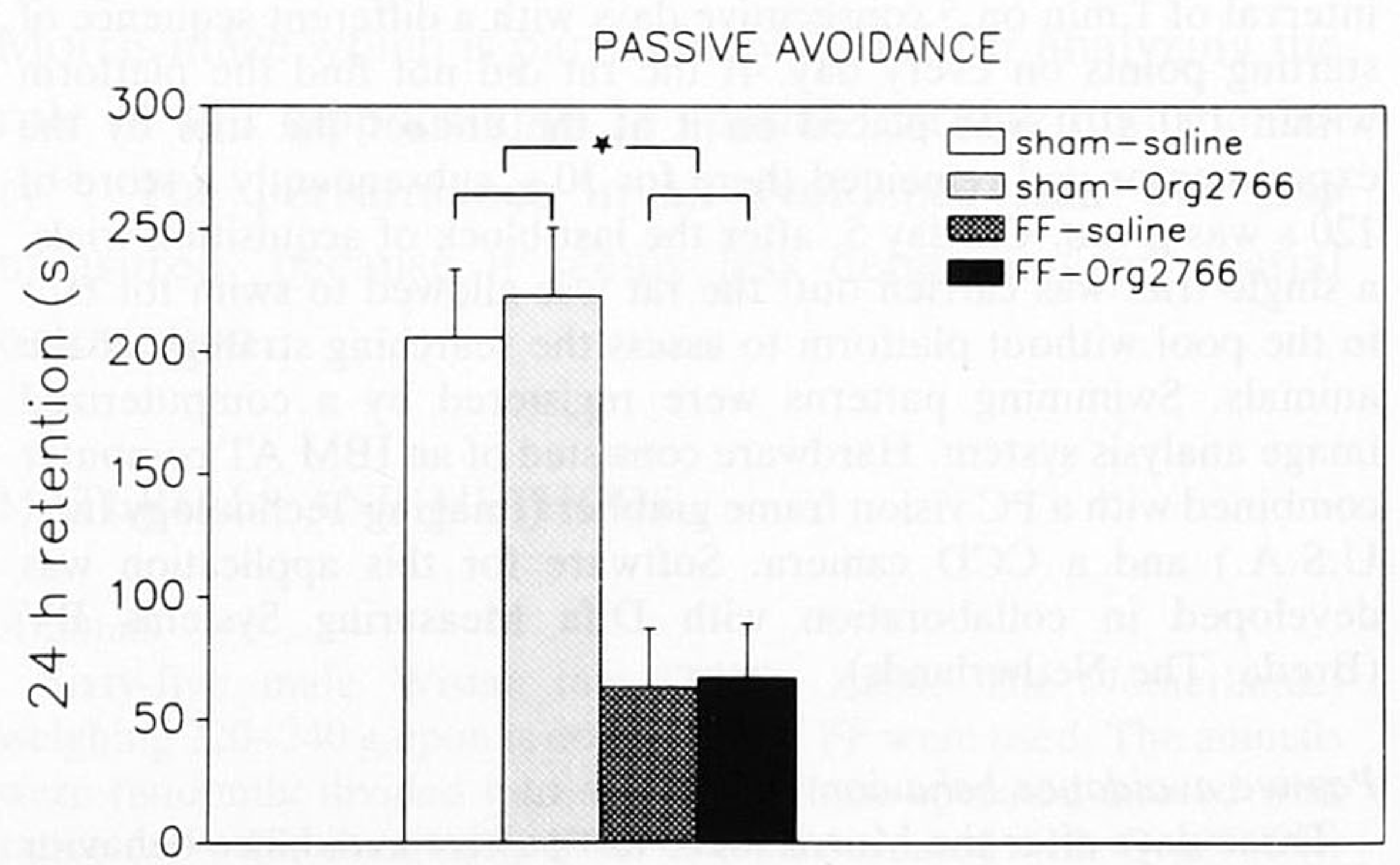

Fig. 5. The latency to re-enter (s; mean \pm S.E.M.), $24 \mathrm{~h}$ after the shock in a passive avoidance task. ${ }^{*}$ Indicates the significant difference between both sham and lesioned groups. 
yielded significant $F$-values for each day for the comparison lesion vs sham-operated. This overall comparison yielded both for latency and distance $P$-values $<0.05$ on days 2, 3 and 4 .

For latencies significant $F$-values were seen for the interaction of drug treatment and surgery on day $3: F_{1,61}$ $=9.6 ; P<0.003$, day $4: F_{1,61}=7.6 ; P<0.008$ and day 5: $F_{1,61}=3.9 ; P<0.05$. On these days a Tukey HSD test for the comparison FF-sal vs FF-Org2766 yielded $P$ values $<0.05$ (see Fig. 2).

Accordingly, for distance significant $F$-values for the interaction of drug treatment and surgery were found on day 3: $F_{1,61}=9.3 ; P<0.003$, on day $4: F_{1,61}=7.6 ; P$ $<0.007$ and on day 5: $F_{1,61}=5.1 ; P<0.027$. A Tukey HSD procedure resulted in significant differences between FF-sal vs FF-Org2766 on these days (see Fig. 3).

In the trial without platform the percentage of the total covered path spent in each quadrant was assessed (see Fig. 4). A Friedman analysis of variance followed by a Wilcoxon test showed that all groups spent more distance in quadrant 2 as compared to the other quadrants $(P<$ $0.05)$. Only for the FF-saline group the distance spent in quadrant 2 did not differ from the distance spent in quadrant 1. However, an ANOVA on distance spent in quadrant 2 yielded a significant difference between the FF-saline group and the other 3 groups: $F_{3,61}=11.1 ; P$ $<0.001$; Tukey HSD, $P<0.05$.

Fig. 5 shows the latencies in a passive avoidance task. Both lesioned groups had shorter latencies compared to the sham-operated groups (Kruskall-Wallis, Chi-square $=26.63, d f(3)$ followed by a Mann-Whitney $U$ test for comparing pairs of groups, $P<0.01)$. No effect from the Org2766 treatment could be established in this task.

No relationship could be demonstrated between behavioral performance and daily body weight from the day of the lesion to the last day of the behavioral experiments.

\section{DISCUSSION}

In line with previous studies using a FF lesion $^{19}$ a disrupted acquisition of spatial orientation was observed. Latencies and swimming distances clearly indicate the facilitatory effect of treatment with Org2766 on the spatial learning performance of lesioned animals. Org2766 was only effective in the lesioned animals and not in the control group. The shortened distance, i.e. a more direct approach to the location of the platform suggests that these effects are not due to enhanced motor activity. It must be emphasized that in the present study behavioral testing was always carried out $48 \mathrm{~h}$ after the last injection of the peptide. Therefore, interference with acute effects of the peptide is very unlikely, as the half time of Org2766 is in the range of minutes ${ }^{31}$.

As mentioned in the Introduction, evidence is available that chronic treatment with Org2766 affects the performance of both brain-lesioned ${ }^{14,20,32}$ and aged ${ }^{15}$, $16,28,29$ rats. However, various results with Org2766 on functional recovery after brain damage have been obtained in other studies ${ }^{11,17,27}$. In the study of Hannigan and Isaacson ${ }^{11}$ rats with lesions restricted to the neocortex were unaffected by prior treatment with Org2766. The rats with hippocampal damage showed attentional deficits; such deficits were attenuated by prior Org2766 treatment. In the study of McDaniel et al. ${ }^{17}$ Org2766 treatment coincided with learning after lesioning of several cortical areas. In their paradigm animals receiving Org2766 committed more errors than their counterparts receiving saline. They concluded that delayed administration coinciding with new learning induced the increase in errors in the peptide treated group. In a study of Rigter et al. ${ }^{27}$ exposure to the peptide increased hippocampal corticosterone receptors in the old rats to parallel the numbers observed in young rats, without improving their behavioral performance.

Apparently, the well established neurotrophic effects of Org2766 are not in all behavioral paradigms recognized as an improvement. The neurotrophic action of neuropeptides on nervous tissue has been assessed in the following paradigms: (1) growth and differentiation of central nervous system neurons in tissue culture ${ }^{3,6,26,30}$; (2) facilitation of axonal outgrowth during neuronal regeneration ${ }^{7,32}$; (3) an increase in corticosteroid receptors, in particular Type I, in aged animals after chronic Org2766 treatment ${ }^{25,27}$.

Several factors can be mentioned, which may explain such an apparent discrepancy between the consistent neurotrophic effects assessed in cell tissue culture and peripheral nerve regeneration on the one hand and a variability in effects at a behavioral level after brain injury on the other hand. First, the present study shows that the effectiveness of a certain treatment seems to be specific for the behavioral test used (compare spatial orientation and passive avoidance), or the combination of the site of the lesion and the test, since no effect of peptide treatment on a spatial orientation task (J.A.D.M. Tonnaer, personal communication) was seen on recovery following lesioning the ventro-medial globus pallidus. Second, the performance of sham-operated animals does not improve by peptide treatment (see the control groups of the studies by Hannigan and Isaacson ${ }^{11}$, Nyakas et al. ${ }^{20}$ and the present study); apparently, the effect of Org2766 is more prominent in animals with a deficit in their performance either due to aging or due to a lesion. Third, pharmacological variables such as the inverted U-shaped dose-response relationship of the 
peptide, duration of treatment (compare aging studies ${ }^{16}$, 28 with lesion studies ${ }^{14,32}$ ) and time of behavioral testing in relation to time of treatment ${ }^{17}$ may be essential for assessing a behavioral efficacy. Thus, the recognition of neurotrophic efficacy of Org2766 measured at a behavioral level may be the result of a complex interaction between features of the damage, the regime of the treatment and the nature of behavioral testing. Moreover, in the central nervous system facilitation of functional recovery is not necessarily exerted via a neurotrophic action of the peptide on injured neurons themselves as has been demonstrated for the peripheral nervous system. For the peripheral nervous system the hypothesis has been put forward that melanocortins mimic a natural occurring peptide signal, which is produced by degenerating nerves ${ }^{8}$, and which stimulate regenerative processes. In the present study it seems unlikely that the difference in performance between the peptide- and vehicle-treated group can be attributed to a difference in

\section{REFERENCES}

1 Ader, R., Weijnen, J.A.W.M. and Moleman, P., Retention of a passive avoidance response as a function of the intensity and duration of electric shock, Psychon. Sci., 26 (1972) 125-128.

2 Allison, R.S., The Senile Brain, Edward Arnold, London, 1962.

3 Azmitia, E.C. and De Kloet, E.R., Neuropeptide stimulation of serotonergic neuronal maturation in tissue culture: modulation by hippocampal cells. In E.R. De Kloet, V.M. Wiegant and D. De Wied (Eds.), Neuropeptides and Brain Function (Progress in Brain Research, Vol. 72), Elsevier, Amsterdam, 1987, pp. 311-318.

4 Barnes, C.A., Nadel, L. and Koning, W.K., Spatial memory deficits in senescent rats, Can. J. Psychol., 34 (1980) 29-39.

5 Bijlsma, W.A., Jennekens, F.G.I., Schotman, P. and Gispen, W.H., Effects of corticotropin (ACTH) on recovery of sensorimotor function in the rat: structure-activity study, Eur. J. Pharmacol., 76 (1981) 73-79.

6 Daval, J.L., Louis, J.C., Gerard, M.J. and Vincendon, G., Influence of adrenocorticotropic hormone on the growth of isolated neurons in culture, Neurosci. Lett., 36 (1983) 299-304.

7 De Koning, P. and Gispen, W.H., A rationale for the use of melanocortins in the treatment of nervous tissue damage. In D.G. Stein and B. Sabel (Eds.), Pharmacological Approaches to the Treatment of Brain and Spinal Cord Injuries, Plenum, New York, 1988, pp. 233-258.

8 Edwards, P.M., Van der Zee, C.E.E.M., Verhaagen, J., Schotman, P., Jennekens, F.G.I. and Gispen, W.H., Evidence that the neurotrophic actions of $\alpha$-MSH may derive from its ability to mimic the actions of a peptide formed in degenerating nerve stumps, J. Neurol., 64 (1984) 333-340.

9 Greene, E. and Naranjo, J.N., Degeneration of hippocampal fibers and spatial memory deficit in the aged rats, Neurobiol. Aging, 8 (1987) 35-43.

10 Greven, H. and De Wied, D., The influence of peptides derived from corticotrophin (ACTH) on performance: structure-activity studies. In (Progress in Brain Research, Vol. 39), Elsevier, Amsterdam, 1973, pp. 429-442.

11 Hannigan, J.H. and Isaacson, R.L., The effects of Org2766 on the performance of sham, neocortical, and hippocampal-lesioned rats in a food search task, Pharmacol. Biochem. Behav., 23 (1985) 1019-1027.

12 Hefti, F., David, A. and Härtikka, J., Chronic intraventricular outgrowth of the transected fibers, accomplished in 2 weeks, due to Org2766 treatment. Org2766-enhanced functional recovery by stimulation of compensatory action of other structures than the lesioned area is an alternative hypothesis, which appears relevant for the central nervous system ${ }^{13}$.

In summary, chronic treatment with Org2766 improves the performance of rats with decreased hippocampal functioning in a spatial orientation task. The present study yields an appropriate paradigm to unravel the different variables mentioned and the mechanisms of action of Org2766 involved in enhanced functional recovery after brain damage.

Acknowledgements. The authors wish to express their gratitude to Marlou Josephy for her advanced biotechnical assistance and Mrs. $\mathrm{M}$. Mens for her help in preparing the manuscript. This study was supported by a Constantijn and Christiaan Huygens Career Development Award to Berry Spruijt received from the Netherlands Organization for the Advancement of Pure Research (N.W.O.)

injections of nerve growth factor elevate hippocampal choline acetyltransferase activity in adult rats with partial septo-hippocampal lesions, Brain Research, 293 (1984) 305-311.

13 Igarashi, M., Ishii, M., Ishikawa, K. and Himi, T., Comparative effect of some reurotrophic agents on balance compensation after labyrinthectomy in the squirrel monkey. In K. Flohr (Ed.), Postlesion Neural Plasticity, Springer-Verlag, Berlin, 1988, pp. 627-634

14 Isaacson, R.L. and Polaswky, A., An ACTH(4-9) analog speeds recovery from septal hyperemotionality in the rat, Behav. Neural. Biol., 39 (1983) 52-59.

15 Landfield, P.W., Modulation of brain aging correlates by long-term alterations of adrenal steroids and neurally-active peptides. In E.R. De Kloet, V.M. Wiegant and D. De Wied (Eds.), Neuropeptides and Brain Function (Progress in Brain Research, Vol. 72), Elsevier, Amsterdam, 1987, pp. 279-300.

16 Landfield, P.W., Baskin, R.U. and Pitler, T.A., Brain-aging correlates: retardation by hormonal-pharmacological treatments, Science, 214 (1981) 581-584.

17 McDaniel, W.F., Davall, E.J. and Walker, P.E., ACTH(4-9) analog can retard spatial alternation learning in brain damaged and normal rats, Behav. Neural. Biol., 52 (1989) 271-278.

18 Morris, R.G.M., An attempt to dissociate 'spatial mapping' and 'working memory' theories of hippocampal function. In W. Seifert (Ed.), The Neurobiology of the Hippocampus, Academic, London, 1983, pp. 405-432.

19 Nilson, O.G., Shapiro, M.L., Gage, F.H., Olton, D.S and Björklund, A., Spatial learning and memory following fimbriafornix transection and grafting of fetal septal neurons to the hippocampus, Exp. Brain Res., 67 (1987) 195-215.

20 Nyakas, C., Veldhuis, H.D. and De Wied, D., Beneficial effect of chronic treatment with Org2766 and $\alpha$-MSH on impaired reversal learning of rats with bilateral lesions of the parafascicular area, Brain Res. Bull., 15 (1985) 257-265.

21 O'Keefe, J. and Nadel, L., The Hippocampus as a Cognitive Map, Clarendon, Oxford, 1978.

22 Olton, D.S., Becker, J.T. and Handelman, G.E., Hippocampus, space and memory, Behav. Brain Sc., 2 (1979) 313-365.

23 Paxinos, G. and Watson, C., The Rat Brain in Stereotactic Coordinates, Academic, New York, 1982

24 Rawlins, J.N.P., Associations across time: the hippocampus as a temporary memory store, Behav. Brain Sci., 8 (1985) 479-497.

25 Reul, J.M.H.M., Tonnaer, J.A.D.M. and De Kloet, E.R., 
Neurotrophic ACTH analogue promotes plasticity of corticosteroid receptor subtype in brain of senescent male rats, Neurobiol. Aging, 9 (1988) 1-7.

26 Richter-Landsberg, C., Bruns, I. and Flohr, H., ACTH neuropeptides influence development and differentiation of embryonic rat cerebral cells in culture, Neurosci. Res. Comm., I (1987) 153-162.

27 Rigter, H., Veldhuis, D.D. and De Kloet, E.R., Spatial learning and the hippocampal corticosterone receptor system of old rats: effects of the ACTH4-9 analogue Org2766, Brain Research, 309 (1984) 393-398.

28 Spruijt, B.M., Brakkee, J.H. and Gispen, W.H., Behavioural plasticity in aging rats: role of melanocortins, $\mathrm{Mod}$. Trends Aging Res., 147 (1986) 495-505.

29 Spruijt, B.M., Van Linder, S. and Gispen, W.H., Improvement of learning and social behavior by an $\mathrm{ACTH}_{4-9}$ analog in aging rats. In: International Symposium on Alzheimer's Disease, Kuopio, Finland, June, 1988, p. 128.

30 Van der Neut, R., Bär, P.R., Sodaar, P. and Gispen, W.H., Trophic influences of $\alpha$-MSH and ACTH(4-10) on neuronal outgrowth in vitro, Peptides, 9 (1988) 1015-1020.

31 Witter, A., Greven, H.M. and De Wied, D., Correlation between structure, behavioral activity and rate of biotransformation of $\mathrm{ACTH}_{4-9}$ analogs, J. Pharmacol. Exp. Ther., 193 (1985) 853-860.

32 Wolterink, G., Van Zanten, E., Kamsteeg, H., Radhakishun, F.S. and Van Ree, J.M., Functional recovery after destruction of dopamine systems in the nucleus accumbens of rats. II. Facilitation by the $\mathrm{ACTH}_{4-9}$ analog Org2766, Brain Research, in press. 